\title{
Desafios da Globalização na Área de Processamento de Polímeros
}

A globalização é hoje uma realidade brasileira. Mais importante do que procurar explicações para esse processo, é estabelecer formas de ação que reduzam as divergências e as distâncias entre todos os envolvidos nas cadeias produtivas, de forma a superar os obstáculos que atravancam a produção. Essas foram algumas das constatações feitas durante o " 2 o Seminário Brasileiro sobre Avanços em Processamento de Polímeros", realizado de 6 a 9 de agosto no Hotel Anacã, em São Carlos, evento organizado pelo Núcleo de Reologia e Processamento de Polímeros (NRPP) do Departamento de Engenharia de Materiais (DEMa) da UFSCar, tendo a promoção da Associação Brasileira de Polímeros, o patrocínio de 13 empresas e entidades e o apoio da Society of Plastics Engineers (SPE - Seção Brasil) e Fundação de Amparo à Pesquisa do Estado de São Paulo (FAPESP).

Os segmentos industriais que utilizam plásticos parecem demandar pouco - o que explicaria o fato de as indústrias do setor, incluídos os transformadores, trabalharem com um grau de ociosidade que pode chegar a $60 \%$ em alguns casos. Por outro lado, o mercado brasileiro como um todo tem crescido muito acima dos padrões mundiais. Muitos dos segmentos que dependem de insumos de plásticos, como o de produtos da linha branca, têm crescido a taxas elevadas, de $300 \%$ a $600 \%$, segundo levantamentos feitos ao longo dos últimos dez meses por institutos como Datafolha, o que, no mínimo, configura uma contradição entre os dados conhecidos nas linhas de produção e a efetiva participação do setor na formação do PIB brasileiro. Essas questões foram debatidas em duas etapas que tiveram como tema "Uma Década de Globalização e Modernização da Indústria de Transformação de Plásticos - Situação atual no Brasil" e "Formas de Ação para Capacitação Tecnológica no Setor de Transformação de Plásticos no Brasil".

\section{Uma Década de Globalização e Modernização da Indústria de Transformação de Plásticos - Situação atual no Brasil}

Como debatedores na primeira seção, realizada dia 7 de agosto, participaram Richard Macret (Rhodia Poliamida), Fernando Nicolosi (Piovan do Brasil), Francisco Assis Esmeraldo (Instituto do PVC) e Ricardo Moreno (Metagal). O presidente da ABPol, Silvio Manrich (UFSCar/DEMa)), atuou como moderador. Na abertura dos debates, que foi realizado por meio da participação individual de cada convidado, Manrich fez uma explanação sobre as condições produtivas do setor de transformação em termos mundiais: "a globalização não nos pegou de surpresa mas estamos todos surpreendidos", disse ele, referindo-se ao fato de que o processo de globalização foi sendo instaurado em termos aparentemente normais, com a adoção de processos e de conceitos que somente vistos em perspectiva deram a noção das alterações econômicas produzidas em escala mundial. "Apesar de muitas contradições, houve melhorias importantes", afirmou Manrich, que citou o setor calçadista como exemplo: "Três anos atrás, esse segmento quase foi destruído. Chegou a perder $40 \%$ das empresas estabelecidas. No entanto, hoje, está recomposto, tendo alcançado um crescimento tal que acabou superando os índices de produção que conseguiu em 1996". O setor de plástico tem passado por um movimento semelhante, explicou Manrich: "a petroquímica se interligou. Não é possível hoje se montar um pólo petroquímico com reatores pequenos. Os reatores têm de atender e competir a nível mundial. Portanto não é em qualquer país que se coloca um reator para produzir polietileno, por exemplo". Por fim, lembrou Manrich, há a conjuntura sócio-econômica a ser considerada e discutida, sobretudo a qualidade das políticas públicas que definem questões como paridade da moeda, patamares dos juros, dificuldades à importação de máquinas, entre outros. "Mas o fato é que as mudanças pegaram muita 
gente despreparada. Apesar disso, a meu ver estamos indo na direção certa".

O primeiro debatedor a se apresentar foi Richard Macret que focou sua preocupações nos desafios tecnológicos presentes na atividade dos transformadores. Ele disse existir hoje fácil acesso à tecnologia, seja em termos de equipamento, de aditivos ou de qualquer componente que torne a produção uma realidade. Os problemas começam, pensa Macret, numa espécie de isolamento produtivo na fase de desenvolvimento de tecnologia. Segundo Macret, os fabricantes de equipamento, que detêm todo um know-how no âmbito da pesquisa de materiais, fazem seu trabalho isoladamente, ainda que em parceria com algumas universidades. O mesmo ocorre com os transformadores e com os fabricantes de aditivos. "O problema está na falta de um desenvolvimento conjunto desses fatores", frisou Macret. "O desafio é que a lucratividade do negócio está em produtos específicos para nichos", ressaltou Macret, "E isso depende de tecnologias específicas. Para que a gente consiga produtos que gerem valor para a empresa, necessitamos de produtos específicos, feitos com tecnologia específica. No meu modo de entender, o desafio que temos é o de trabalharmos juntos no sentido de juntar diferentes competências para produzir alguma coisa realmente nova e criativa".

$\mathrm{Na}$ opinião de Fernando Nicolosi, um aspecto precisa ser destacado quando se pensa em processos tais como globalização: "a primeira coisa a ser entendida é a competitividade, que é o ato de você participar de um processo de disputa, que pode ser saudável ou não. E isso quer dizer atender uma necessidade de mercado a partir de alguns requisitos muito simples até; significa você oferecer quantidade, qualidade ao custo desejado, no prazo que toda a cadeia precisa e com um serviço de suporte adequado". A partir da correta e eficiente equação desses fatores, pensa Nicolosi, é possível enfrentar os obstáculos em outras frentes. "É preciso ter a tecnologia para que se possa desenvolver um trabalho de qualidade. Em segundo lugar é preciso ter os meios de fazer essa tecnologia funcionar. Por fim, será preciso trabalhar o humanware. São fatores fáceis de debater, de comentar, mas na prática não são tão simples assim". Fundamental, no caso brasileiro, pensa Nicolosi, será superar as questões que tornam o "ambiente" produtivo pouco estimulante. "Como é possível produzir num país onde o ambiente produtivo não ajuda. $\mathrm{O}$ dinheiro mais barato hoje no Brasil é a TJLP, Taxa de Juros de Longo Prazo, acrescidos na prática de $4,5 \%$, o que dá hoje $19 \%$ ao ano, um custo de dinheiro altíssimo para os padrões mundiais. Como um pais como o nosso pode acompanhar a demanda de automotiva, feita de bilhões de dólares, sem ter uma infra-estrutura nacional?"

Francisco Assis Esmeraldo, representante do Instituto do PVC abordou questões relacionadas à reciclagem: "o mundo hoje está tão descartável que a reciclagem é uma necessidade imperativa", disse ele. Esmeraldo lembrou que a tarefa de reciclar deve envolver o comportamento de consumidores e de produtores, o qual estimulado deve seguir posturas mais avançadas, como a coleta seletiva de lixo.
Somente uma prática baseada em novos critérios é que levará, pensa Esmeraldo, a um efetivo conceito de desenvolvimento sustentado, que em termos mais singelos, afirmou ele, nada mais é do que produzir hoje sem comprometer o amanhã.

\section{Seção de Debates com membros da platéia}

Na opinião de Edson Simielli (GE Plastics) a globalização é uma realidade. "Provavelmente os nossos amigos asiáticos devem estar fazendo um seminário como este para discutir formas de atrair as grandes empresas que estão preferindo investir no Brasil. A questão da contradição entre demanda e produção foi tornada explícita pelo pesquisador Gil de Carvalho (Instituto Politécnico da UERJ): "não produzimos nem a capacidade instalada", declarou ele. Carvalho disse não acreditar na existência de barreiras tecnológicas. "A questão é como facilitar o acesso às tecnologias, superando-se as barreiras que são comerciais. Se chegássemos a produzir pelo menos o que a capacidade instalada permite estaríamos ainda fazendo um quarto do que os países de primeiro mundo consomem". Ao analisar essa questão, Edson Simielli, concordou com a noção de que os índices de ociosidade são grandes mas advertiu: "Para atrair empresas que sejam consumidoras finais de plásticos de engenharia, precisaremos ter empresas de ponta na área de transformação, altamente produtivas em termos de tecnologia de transformação". Fernado Nicolosi deu um exemplo prático em reforço aos argumentos de Simielli. Ele disse conhecer empresas com problemas sérios, por 
exemplo em policondensação, com resultados desastrosos em termos de produtividade e rentabilidade. Citou exemplo de empresa que faz dosagem de componentes especiais manualmente, sem equipamentos precisos como dosadores gravimétricos. "Se não houver uma mudança no lado dos incentivos produtivos, cada vez mais empresas estrangeiras virão para o Brasil para comprar empresas nacionais".

Esse conjunto de problemas, disse posteriormente Silvio Manrich, aponta a necessidade urgente de as empresas brasileiras adotarem uma postura mais aberta: "finalmente percebemos que a globalização beneficia também os países em desenvolvimento, como o Brasil, com impactos importantes na organização das empresas, que precisam aprender a olhar para fora, e a interagir de maneira eficaz com o mercado".

Edson Simielli disse que esse seminário teve o papel de posicionar os profissionais e estudiosos envolvidos diante do atual estado das coisas: "ficou claro que a globalização bem ou mal está aí, como aliás em todos os lugares. E a meu ver traz muitos benefícios porque vem forçando as empresas do setor a rever seus planos e seus focos de ação, sobretudo no Brasil. É preciso reconhecer que foi esse processo que provocou uma profunda transformação no parque produtivo. Com a vinda das multinacionais, competidores globais por excelência, houve uma redefinição do perfil do setor, com fusões, compras de empresas, investimentos novos. Nesse sentido, as cadeias produtivas comportam agora uma maior aproximação dos vários interlocutores".
Para Silvio Manrich, ao final do debate pode-se concluir que a globalização é um fenômeno multifacetado, que tanto beneficia quanto impõe uma lógica de produção aos países emergentes, como o Brasil. Daí a importância de as empresas brasileiras do setor adotarem uma visão estratégica que, necessariamente, passa por uma ampliação de horizontes, um "olhar para for a e de for a para si mesmas", conceitua Manrich. E os dados disponíveis mostram a urgência dessa atitude: "Há dez anos havia cerca de 300 indústrias processando $\mathrm{PVC}$, hoje são 50", adverte.

\section{Formas de Ação para a Capacitação Tecnológica no Setor de Transformação de Plásticos no Brasil}

No segundo debate, tendo como moderador Edson Simielli, reuniram-se o professor Afonso Fleury (Escola Politecnica da USP e da Fundação Vanzolini), Rogério Araújo (Escola Técnica Tupy, de Joivinlle-SC), Osmar Zanelatto, (Escola Senai Mário Amato-SP), Pau- lo da Colina (Instituto Nacional do Plástico), Silvio Manrich (como coordenador do curso de engenharia de materiais da UFSCar e presidente da ABPol) e Ernst Spieth, (Society of Plastics Engineer). O tema em discussão era: "Formas de Ação para a Capacitação Tecnológica no Setor de Transformação de Plásticos no Brasil”.

$\mathrm{Na}$ abertura dos debates, após efetuada a apresentação dos convidados, Osmar Zanelatto lembrou que o desenvolvimento tecnológico tem gerado assimetrias no desempenho econômico dos países, que repercutem nos fatores econômicos e sociais, os quais podem ser agravados por condutas governamentais: "na verdade há um grande paradoxo, a empresa precisa de um grande estoque de capital para investir em tecnologia, o qual é muito caro. O governo se utiliza desse capital privado para pagar suas dívidas, é um péssimo poupador, e esse capital que deveria ser usado em investimentos produtivos e inovação tecnológica e capacitação dos seres humanos, acaba tendo outras funções". Para Zanelatto, o traba-

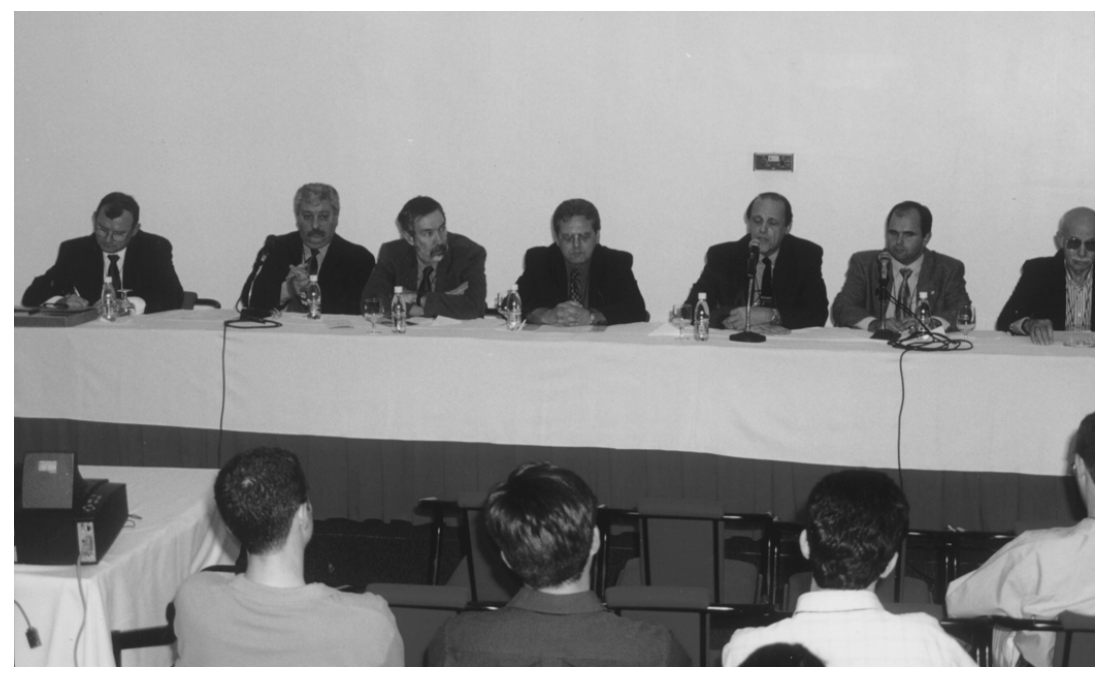

Composição de debatedores " $2^{\circ}$ Seminário sobre Avanços em Processamento de Polímeros”, Silvio Manrich, Paulo Dacolina, Afonso Fleury, Edson Simielli, Osmar Zanelatto, Rogério Araújo e Ernst Spieth. 
lhador brasileiro não estava preparado para mudanças drásticas no cenário trabalhista, ao contrário do que ocorreu em países do Primeiro Mundo, como Estados Unidos, onde a mão-de-obra foi reaproveitada satisfatoriamente após as mudanças tecnológicas. Zanelatto lembrou ainda que, paralelamente, ao se modernizarem as empresas desempregam gente, fenômeno que acirra as disputas sociais. "Não podemos nos esquecer disso", advertiu.

O segundo debatedor a se manifestar foi Rogério Araújo que fez um balanço das atividades da escola Técnica Tupy, que nasceu em 1959 dentro da Fundação Tupy, gerida por uma fundação sem fins lucrativos que tem na administração um conselho formado por representantes de poderes públicos e de associações empresariais. A escola atende mais de três mil alunos, cursando o segundo grau regular, segundo as diretrizes do Ministério da Educação, conjuntamente com atividades curriculares voltadas à formação técnica. Desde 1998, a entidade começou a ministrar cursos de tecnológos em nível superior. E no meio deste ano começou a funcionar o curso de Tecnológo de Materiais, com opção ao estudante de escolher entre processamento de metais ou de polímeros. Segundo Araújo, a entidade administradora tem buscado identificar as necessidades das indústrias e gerar cursos de capacitação profissional, "sempre tendo como enfoque a qualidade técnica dos interessados"

Na condição de representante do Instituto Nacional de Plástico, Paulo Dacolina explicou como surgiu a entidade, em 1989, como resultado das associações brasileiras repre- sentativas de todos os segmentos produtivos do setor de plásticos. Segundo Dacolina, o Instituto tem diversos projetos que apontam caminhos para a capacitação tecnológica. "Nosso objetivo final é colaborar no desenvolvimento da cadeia produtiva, harmonizando os movimentos das entidades representativas". O segmento de plásticos, disse Dacolina, tem apresentado crescimento anual da ordem de $10 \%$ ao longo da última década, "um dos poucos setores da nossa economia que cresce nessa proporção" e sob a perspectiva de que essa taxa manter-se-á elevada no curso dos próximos anos. "Até 2008, a nossa cadeia produtiva deve dobrar de tamanho", reforçou o debatedor. Do universo de cinco mil empresas do setor, $95 \%$ são constituídos por empresas de micro, pequeno e médio portes, fator levado em conta pelo INP, disse Dacolina, "por que elas são os embriões da nossa indústria". No atendimento desse universo, explicou Dacolina, três critérios básicos são observados. $\mathrm{O}$ primeiro é o da capacitação tecnológica. Dacolina falou da experiência posta em prática pelo Projeto Prumo, uma iniciativa que tem no IPT o carro-chefe de apoio ao setor, com recursos do SEBRAE e da FAPESP. Nesse âmbito ainda, disse ele, existe um programa de certificações ISO para as pequenas empresas. O segundo ponto, informou Dacolina, diz respeito à normalização dos produtos, sobre os quais o INP tem formado parceria com comissões técnicas da Associação Brasileira de Normas Técnicas. "Tudo isso para fortalecer a imagem dos produtos plásticos e do segmento como um todo". O terceiro aspecto reside na capacitação profissional. Dacolina citou even- tos realizados para alavancar idéias que gerassem propostas concretas de ação para que um conjunto de medidas seja posto em prática, destinado a contemplar as diversas realidades brasileiras. "Essa é nossa função, acender o estopim e sair de perto", disse.

\section{Seção de Debates com membros da platéia}

Silvio Manrich lembrou atividades que vem sendo geradas no âmbito do Estado de São Paulo no sentido de aprofundar as formas de capacitação profissional. Manrich lembrou que, em termos de recursos humanos, o setor tem na estrutura de emprego da mão-de-obra uma forma de pirâmide com um número expressivo de técnicos de nível básico, a parte frágil da pirâmide, onde o operador, por falta de preparo, ainda se espanta com uma máquina importada, com avisos e instruções expressos em inglês. "Precisamos fazer com que toda a pirâmide entre em consonância, isto é, tenha uma base adequada às necessidades do País, que precisa continuar crescendo ao mesmo tempo que enfrenta os desafios trazidos pela globalização". Quanto ao ápice dessa pirâmide, Manrich lembrou existirem 16 universidades no País que formam engenheiros de materiais, em vários níveis. Além disso, crescem os cursos de formação de tecnólogos. Os problemas mais sérios hoje encontram-se entre os técnicos de nível médio, disse Manrich, que precisam de mais atenção, "aquele que nem está no chão-de-fábrica, nem ocupa cargo de nível superior, mas que já começa a enfrentar problemas de desemprego, por falta de requalificação e principalmente pela centralização das atuais esco- 
las”. Esse fato aponta para a necessidade da regionalização da formação de pessoal, lembrou Manrich, até para que se evite a migração de profissionais que quase sempre retornam a seus Estados de origem, geralmente do CentroSul. Ernst Spieth, por sua vez, lembrou, citando relato do jornal Gazeta Mercantil, que as empresas transnacionais, para aumentar a produtividade, distribuem tarefas entre os países de seu interesse, podendo gerar um novo processo de colonização. Spieth disse que entre o rol de medidas posto em prática para capacitar os profissionais brasileiros de modo a prepará-los para fazer frente aos novos tempos, foi, seguindo o modelo adotado pela ABPol., franquear o acesso dos interessados brasileiros aos fóruns de debates internacionais, com patrocínio garantido, além de cursos com conferencistas internacionais. Os resultados desses quatro anos não foram muitos animadores, disse Spieth. Os custos ficaram muito altos e inviabilizaram a participação dos interessados. "Além disso, as empresas brasileiras ainda impedem a participação dos seus funcionários."

$\mathrm{Na}$ sua participação, o professor Afonso Fleury levantou três aspectos que residem na lógica do processo de globalização. Citando estudos de pensadores americanos, Fleury lembrou para a ascensão daquilo que chamou de economia do conhecimento, este será o fator diferenciador. Nesse sentido criticou duas medidas postas em prática pelo Governo Federal, a institucionalização das zonas de transformação industrial, e a redução de taxas para importação de equipamentos.

Fazer o equipamento quer dizer consolidar conhecimento, advertiu Fleury. "Precisamos tomar cuidado com um fenômeno. Alguém já disse que estamos virando cada vez mais um país de montagem. Ou seja, estamos fazendo engenharia de produção e esquecendo as outras engenharias. Acho necessário gerar um tipo de ação que junte empresas, entidades e universidade". Às universidades, lembrou Fleury, cabe o papel de prospectar cenários, de modo a prever quais cenários tecnológicos iremos en- contrar nos próximos anos, "sem esse norte estaremos sempre reagindo aos avanços realizados em outros países".

Para Edson Simielli, pelo que os participantes do debate demonstraram, "fica clara a existência de uma série de medidas isoladas, nas mais diversas partes do Brasil. Muita coisa está sendo feita mas persiste a sensação de que nada está sendo feito". O entendimento dessa nova realidade que se verifica na prática, ressaltou Simielli, revelou-se como um dos frutos do debate especificamente e do evento como um todo, "um caminho que precisa ser estimulado", afirmou.

O professor José Alexandrino de Sousa, coordenador do seminário e diretor da $\mathrm{ABpol}$, apresentou números que confirmam a percepção de Simielli: de 164 pessoas inscritas nos vários segmentos do $2^{\circ}$ Seminário, 148 estiveram presentes nos dois debates realizados. "Vemos assim cumpridos os objetivos maiores do encontro, qual seja, colocar lado a lado os representantes das universidades, das entidades de fomento e da atividade industrial no setor". 